\title{
Chromosomal Heteromorphism with Reference to Cancer and Reproduction in Human: An Appraisal
}

\author{
Nidhi P. Shah ${ }^{1,2}$, Parth S. Shah ${ }^{1,3}$, Jeanny Dominic ${ }^{1}$, Bhavini S. Shah ${ }^{1}$, Sandip S. Shah ${ }^{1}$, Mandava V. Rao ${ }^{1,4}$ \\ ${ }^{1}$ Neuberg Supratech Referral Laboratory, Ahmedabad-6, India \\ ${ }^{2}$ Division of Genetics, Boston Children Hospital, Boston, Massachusetts, USA \\ ${ }^{3}$ Division of Hematology and Oncology, Dart mouth Hitchcock Medical Centre, Lebanon, New Hampshire, USA \\ ${ }^{4}$ School of Sciences, Gujarat University, Ahmedabad-9, India
}

Corresponding author: Mandava V. Rao; manvrao@gmail.com

Received 12 October 2019;

Accepted 15 November 2019;

Published 24 November 2019

\begin{abstract}
Background and Objectives: Human cell nucleus has, the genome consisting of euchromatin and heterochromatin. The euchromatin has generich and actively functional. The heterochromatin has two components namely constitutive and facultative, where the former is highly polymorphic. It is related to numerous diseases like cancer and infertility which is now well known, though it was earlier thought to be inactive; hence the implication of these polymorphic variants of chromosomes is reviewed with respect to acrocentric and non- acrocentric types. Methodologies: The polymorphic variants can be detected by C, G, Q and R banding techniques. We usually follow G band preparation of karyotypes following World Health Organisation (WHO) manuals and their role in cancer and reproduction is reviewed. $\underline{\text { Review and }}$ Conclusion: It is emphasized that most of the $\mathrm{p}$ and $\mathrm{q}$ arms of $1,9,16, \mathrm{D}$ and $\mathrm{G}$ groups and $\mathrm{X}$, $\mathrm{Y}$ chromosomes exhibited polymorphism which are related to cancerous and infertile conditions in both sexes. Data on few non-acrocentric chromosomes like 2, 4, 8, 10, 12, 18, 19 and 20 are not available. Our review however indicated that the evaluation of specific heteromorphic variants needs to be detected using specific probes for confirmation of anomaly to assist affected cases, though earlier data indicated ambiguous information with few cases analyzed regarding assisted reproductive technologies and malignancy condition. This appraisal thus would play a key role in human chromosomal heteromorphic abnormalities and recommend genetic tests and counseling ultimately made available to the affected cases.
\end{abstract}

Keywords: Acrocentric and non acrocentric chromosomes, Heterochromatin, Heteromorphic, Human, Infertility, Karyotypes, Malignancy.

\section{Introduction}

Recent studies on cell nucleus have revealed that the nuclear genome has euchromatin and heterochromatin, two functional units present on chromosomes. The euchromatin has the most active portions of genome with gene rich. The heterochromatin has two types i.e. Constitutive and facultative. The constitutive type is a stable form, composed of satellite DNA I, II or III units and is known to be highly polymorphic not coding the protein and unstable. Facultative is not rich with satellite DNA and is not very polymorphic like inactive $\mathrm{X}$ chromosome (Barr body). The role of heterochromatin in human genome is remained unknown as it has no functional and phenotype effect including cancer. ${ }^{[1,2]}$ It now is known that heterochromatin is not inert and has multiple functions in a cell and organismal viability in multi-cellular eukaryotes. Genes required for viability, fertility and cancer are thought to be present in it required for chromosomal inheritance. It also plays a role in spindle attachment and chromosome movement, meiotic pairing and sister chromatid cohesion. ${ }^{[3-7]}$

\section{Methodology and Classification}

Studies on human chromosomes had revealed that there was a great deals of polymorphism with certain pairs of complement in particular pairs of $1,9,16$, and $\mathrm{Y}$ as well as D and G groups which are of interesting. Others also exhibit to certain level ${ }^{[4,7]}$ Thus these chromosomes included are non-acrocentric (usually paracentric, acrocentric, and distal region of $\mathrm{Y}$ chromosome). The term heteromorphism is especially applicable to normal variants observed before Q, C, R and G banding techniques. ${ }^{[8]}$ In 1960/ 1966, chromosomes were divided into A-G groups based on their relative sizes and position of the centromere. The $\mathrm{X}$-chromosome fell in the $\mathrm{C}$ group, whereas $\mathrm{Y}$ was in $\mathrm{G}$ group due to lack of satellite and distinctive morphology. In 1963 prominent secondary constrictions were identified near centromere of chromosome 1 in group A, 9 (in group C) and 16 (in group E). By 1966, it was generally noticed that these regions and the variable length of $\mathrm{Y}$ including variations in short arms of the D/G chromosomes using Q, G and C-bandings became widely used. ${ }^{[9]}$ The $\mathrm{Q}$ and $\mathrm{C}$ bandings are possible to localize regions variable in size and staining to specific chromosomes. These bandings revealed distinct classes of heteromorphisms. The most listing heteromorphism by the use of $\mathrm{Q}$ banding was observed in variations in length of long arm of $\mathrm{Y}, 3,4,13-15$ and $21-22,,^{[10-13]}$ although $\mathrm{G}$ banding 
technique became generally used for identification of chromosomes. $^{[5,8]}$

As these are highly polymorphic, we call it as polymorphic heterochromatin sites. This phenomenon is familial and follow Mendelian inheritance with low mutation rate. ${ }^{[3]}$ These polymorphic variants occur due to the following reasons; short arm with them and secondary constriction sites, satellite stalks satellite themselves short arm with genes and breakages are exchangeable of leading to Robertsonian and structural rearrangement in man. These chromosomal heteromorphisms also include various sizes of repeated DNA sequences in the genome like various sizes of heterochromatin blocks as cited earlier. These are commonly seen on non-acrocentric chromosomes on long arms (q) of 1, 9, 16, short arms (p) of acrocentric chromosomes and distal heterochromatin of $\mathrm{Y}$ chromosome. Thus increase/decrease in length of heterochromatin region of above chromosomes like $1 \mathrm{qh}+, 9 \mathrm{qh}+$ and 9qh- and short arm of D and G groups such as 13Ppsk+, 13ps+, $14 \mathrm{ps}+, 21 \mathrm{ps}+, \mathrm{Yp}+$ etc. are notified. ${ }^{[7,14,15]}$ This frequency occurs in more individuals ${ }^{[3]}$ and cause reproductive anomalies, mental retardation and cancer. ${ }^{[16-18]}$ Chromosomal heteromorphisms are also important in paternity testing, maternal cell contamination during amniocentesis, chorionic villus sampling (CVS) and in tracing the origin of the extra chromosomes in trisomies and other types. Heterochromatin hence mainly plays a role in genome function, which needs to be searched, though still the genes present in these DNA units are to be identified and their role in unclear gene functions pose a challenge in molecular biology.

\section{Cancer}

The possible role of constitutive heteromorphism in the development of neoplasia has been explored by many researchers, using $\mathrm{G}$ and $\mathrm{C}$ banding methods. ${ }^{[9,19,20,21,22]}$ Many workers have found the correlation between constitutive heterochromatin heteromorphism in chromosome 1 and development of different types of neoplasms, such as ovarian cancer, carcinoma of cervix, breast cancer, malignancies of the head and neck, solid tumors, carcinoma of the colon and rectum, bladder carcinoma, chronic myeloid leukemia (CML), acute myeloid leukemia (AML) and multiple myeloma. ${ }^{[22-28]}$ Contrast results were also noticed by Kivi and Mekelsaar ${ }^{[24]}$ in regard to ovarian and testicular tumors. Some of the studies report also support association of malignancy with heteromorphism of chromosome 9 and $16 .^{[22]}$ Berger et $\mathrm{al}^{[17]}$ noticed heteromorphism of constitutive heterochromatin with $G$ band positive in human chromosome 1, 9, 16 in peripheral lymphocytes of 54 breast cancer cases. Heteromorphism of $\mathrm{C}$ bands on chromosome 1, 9 and 16 with different premalignant and malignant diseases were reported in the form of solid tumors and hematologic disorders in literature by Berger et al. ${ }^{[17]}$ The parameters of heterochromatic regions analysed were of relative size, symmetry-asymmetry within homologous pairs and prevalence of inversions. These authors found differences between control and diseased cases with respect to $\mathrm{C}$ band size of chromosomes \#1, \#9 and \#16 and incidence of inversions. ${ }^{[17]}$ Suciu $^{[29]}$ in his study in patients with solid tumors (101) and along with controls (85) found that $\mathrm{C}$ bands of constitutive heterochromatin polymorphism associations were between \#1 and \#9 chromosomes and between chromosome \#9 and D acrocentrics. It also concluded the involvement of constitutive heterochromatin of \#1 in malignant disease in solid tumor patients. Chromosome analysis was carried out in G and C banding from PBLCs of 19 families with familial occurrence of cancer. Distinct heteromorphism in the chromosome 1qh+ (Fig.2A,B) was detected in $15(79 \%)$ of them. ${ }^{[22]}$ We also noticed heterochromatin polymorphism in \#1 chromosome in hematologic neoplasia cases recently. ${ }^{[30]}$ Earlier the frequency of heterochromatin polymorphisms in patients with malignant disease in blood cultures of 23 patients and with controls having free of cancer and same sex were also included. It concluded that no significant differences were noticed in both groups, except with \#1 chromosome in breast cancer. ${ }^{[25]}$ However other chromosomes 9 and 16 were also reported in varieties of cancer types, ${ }^{[17,22]}$ where it is more prone to disease. ${ }^{[22]}$ Atkin ${ }^{[19]}$ studied first heteromorphism with C - banding positivity to ovarian carcinoma. Much work needs to be tackled on the role of heterochromatin in molecular oncology.

The role of constitutive heterochromatin is unclear at present in cancer, but a review of literature reveals that a trend in cytogenetic studies favoring an association between malignancies and heteromorphism distribution differences in cancer patient and controls. This poses a question regarding the transpositions of DNA sequences in repetitive DNA of heterochromatin. Another consequence is that heterochromatin plays a role in mitotic as well as in meiotic pairing and segregation. These conditions indicate that heterochromatin polymorphism might thus be related to aneuploidy or partial homozygosity reported ${ }^{[17]}$ in malignant tissue samples [Fig.1, Table-1].

Table 1: Summary of chromosomal heteromorphism in cancer and reproduction

\begin{tabular}{|l|l|l|l|}
\hline Chromosome no. & Heterochromatic region & Possible effects/ dysfunction & References (2000 onwards) \\
\hline 01 & 1 1qh+/1qh-, 1qh, inversion & $\begin{array}{l}\text { Miscarriage/Azoospermia } \\
\text { premalignant/malignant disease }\end{array}$ & {$[3][5][6][8][14][15][32][45]$} \\
\hline 03 & Inv.3 & BOH & {$[7][14]$} \\
\hline 05 & Inv 5 & Reproductive effects & {$[15][37]$} \\
\hline 06 & Inv.6 & Infertility in female, Miscarriage & {$[32]$} \\
\hline 07 & Inv.7 & Reproductive effects & {$[15][37]$} \\
\hline 09 & 9 qh+, 9qh- and inv 9. & Cancer, Infertility & {$[2][4][5][6][7][8][14][15][34][36]$} \\
& & & {$[37][45][58][60][74]$} \\
\hline 11 & $11 q$ ins. & No effects & {$[45]$} \\
\hline 13 & ps+ & Reproductive effects & {$[2][3][4][7][14][15][32][42][64][74]$} \\
\hline 14 & ps+ & RMC, Pregnancy loss, Other reproductive effects & {$[2][3][4][7][15][32][36][42][64][74]$} \\
\hline $15 *$ & ps+ & Pregnancy loss, BOH, Reproductive failure & {$[2][4][7][14][15][32][36][42][64][74]$} \\
\hline 16 & qh+, qh-, inversion & $\begin{array}{l}\text { Recurrent miscarriage, Infertility, } \\
\text { Premalignant/malignant disease }\end{array}$ & {$[4][5][6][8][14][15][32][45][74]$} \\
\hline 17 & & No reproductive effect & {$[33]$} \\
\hline 21 & Inversion & Reproductive effect & {$[7][32][42][74]$} \\
\hline 22 & ps+ & Pregnancy loss, BOH, Reproductive failure & {$[7][32][42][74]$} \\
\hline
\end{tabular}




\begin{tabular}{|l|l|l|l|}
\hline $\mathrm{Y}$ & $\begin{array}{l}\text { qh+, Yp+, inversion, } \\
\text { Large (Y) }\end{array}$ & $\begin{array}{l}\text { ART failure, Trisomy 21 risk, infertility, } \\
\text { Abortion }\end{array}$ & {$[7][32][49][50][51][52][72][74]$} \\
\hline $\mathrm{X}$ & Inactivation & Gene expression alteration & {$[1][2][3][4][7]$} \\
\hline
\end{tabular}

BOH : Bad obstetric history; Chromosome variants of 2,4,8,10,12,18,19 and 20 are unavailable.

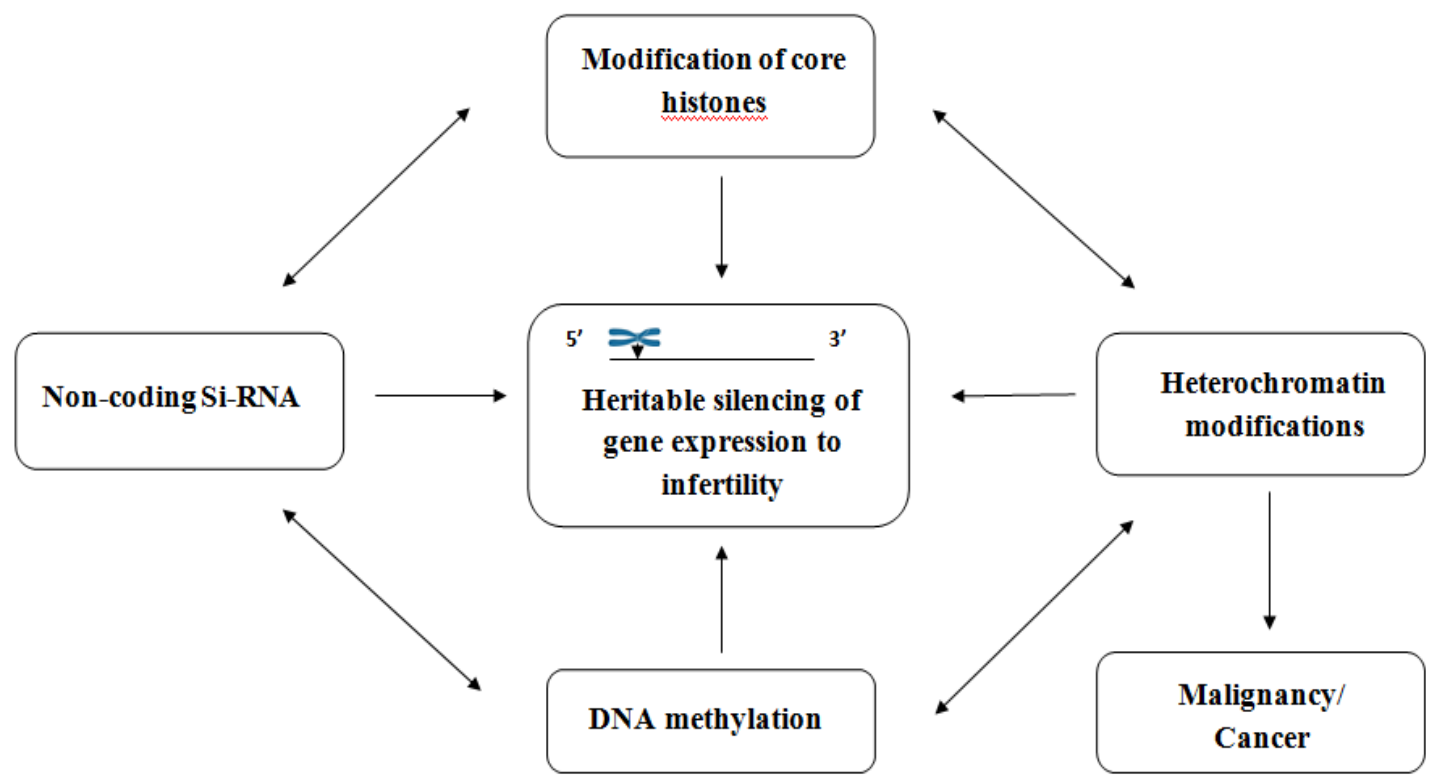

*Non-acrocentric and acrocentric chromosomes

Figure 1: Chromosome heteromorphism*, cancer and infertility association modified from berger et al [17] and minocherhomji et al [4] respectively.

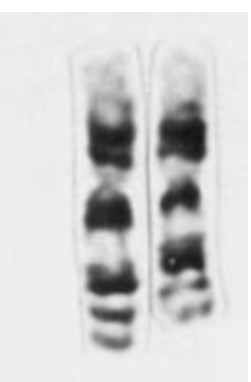

Figure. 2A,

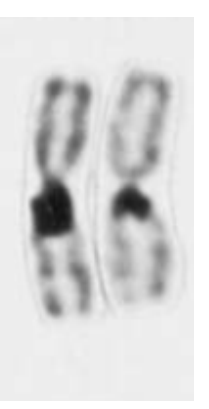

Figure. 2B

Figure 2: 1qh Heteromorphism in cancer with g-banding(a) and c-banding(b) [22]

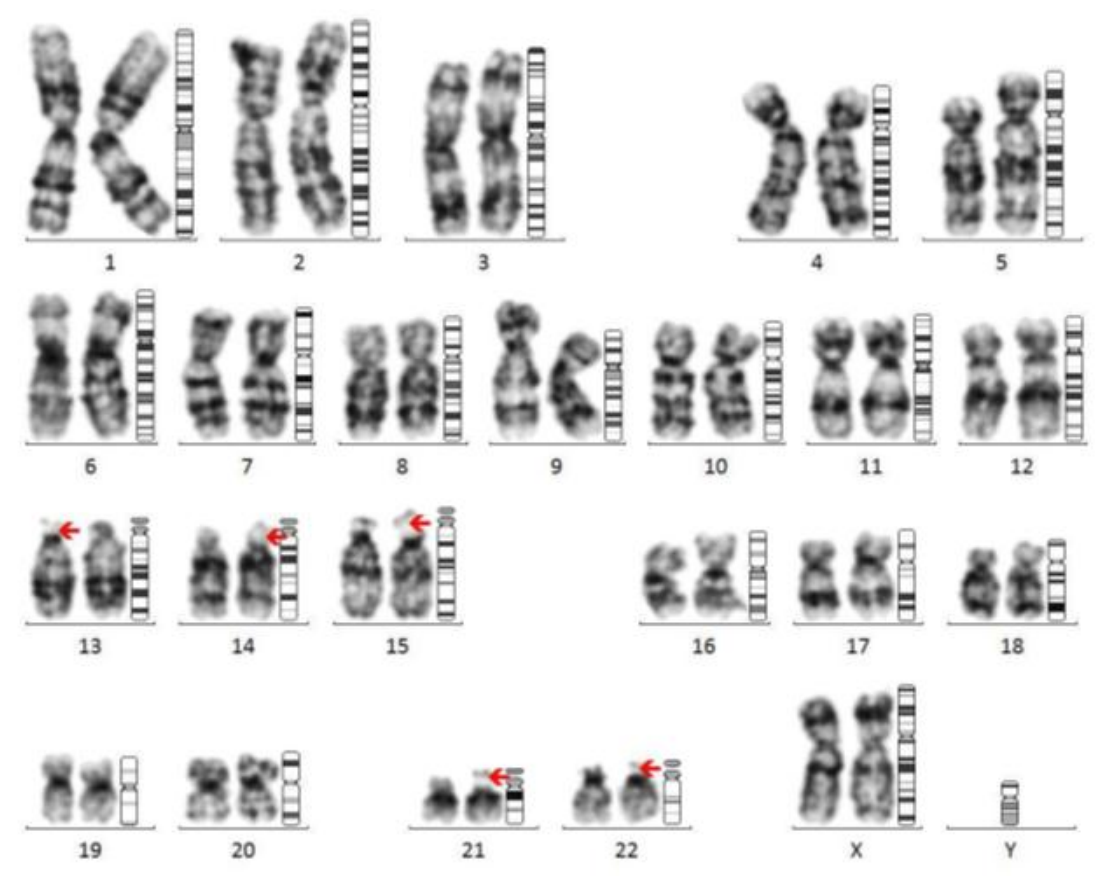

Figure 3: D and G group heteromorphism in a female with infertility- $\mathrm{g}$ banding [7]. 


\section{Development and Reproduction}

Using quantitative analysis of C - band heteromorphism of chromosomes 1, 9, 16 in 200 Delhi new borns showed no significance differences between sexes, but polymorphic variants occur in newborn also. ${ }^{[31]}$ This report has the possible role of the heteromorphism in ethnical/racial ovarian and in developmental disturbances in human population with $\mathrm{C}$ - banding. Euchromatin heteromorphism is less whereas, more heteromorphic variants have been described. ${ }^{[6]}$ Saran et al. ${ }^{[32]}$ showed in their result that $1 \mathrm{ph}+$ of chromosome 1 is related to recurrent miscarriages in addition to malignancy. Additionally, inversion/inverted segment of chromosome 1 might lead to synaptic failure during homologous chromosome pairing leading to male infertility. ${ }^{[15,32]}$ Chromosomal polymorphism of 1, 7,11, 17 autosomes with $\mathrm{D}$ and $\mathrm{G}$ groups were added in their studies too. Heteromorphism of 17 in a case was reported by insertion of q12 leading a novel chromosomal variant ${ }^{[33]}$ but no effect on fertility. Normal spermatogenesis occurs. The polymorphic $16 \mathrm{qh}+/$ - detected by Saran et al. ${ }^{[32]}$ and Pokale $^{[15]}$ was correlated with infertility in females particularly T21 risk in pregnant woman during the analysis of infertile and amniocentesis cases, but number is restricted to few $(3 / 230,1 / 463)$ respectively.

Variants of chromosome 9 including inv(9) depicted maximum variations which included $9 \mathrm{qh}+/-$ and $\operatorname{inv}(9)$ in their studies of Saran et al. ${ }^{[32]}$, Pokale ${ }^{[15]}$, Vaghasia et al. ${ }^{[7]}$, Mierla and Stoian ${ }^{[34]}$, Purandare et al. ${ }^{[14]}$, Dana and Stoian ${ }^{[35]}$, Christofolini et al. ${ }^{[3]}$ and Rao et al. ${ }^{[37]}$ using GTG banding. Further, inv(9) is known to occur in 1-3\% population but inv(9) (p12q13) was related to dysmorphic features and congenital anomalies. Purandare et al. ${ }^{[14]}$ coined that inv(9) contributed $16 \%$ of total inversions $(25 \%)$ comparatively. In $\mathrm{BOH}$ couples, its frequency was more. Hence, pericentric $\operatorname{inv}(9)$ is associated with recurrent miscarriages, infertility and congenital anomalies. ${ }^{[2,38-45]} \operatorname{Inv}(9)$ has been associated with chromosomal non-disjunction and has variable effects on spermatogenesis from azoospermia to severely altered sperm count, morphology, motility and meiosis segregation. During meiosis-I, a loop (tetrad formation/chiasmata) is formed in chromosomes with inversion and this can lead to production of abnormal gametes. Carriers of such inversions are at risk of abnormal karyotype in offsprings. Such inv(9) might lead to meiotic disturbances and it is known to be associated with T21 and mosaic T21. ${ }^{[2]}$ Pericentric inv(3), inv(5), inv(6), inv(7) are also less in frequency and need to be studied with other molecular methods to understand disease association ${ }^{[15,37]}$ along with chromosome 11. ${ }^{[6,33]}$ Polymorphic variants of non acrocentric chromosomes 2, 4, $8,10,12,18,19$ and 20 are not yet available in the literature to review so far as our knowledge is concerned.

Large polymorphic variations in the length of centromeric heterochromatin on ' $\mathrm{q}$ ' arms of chromosome 1, 9, 16 and $\mathrm{Y}$ were documented (1qh+, 9qh+, 16qh+, Yqh+, inv(Y), inv(16)) and these were less in frequency comparable to inv(9). ${ }^{[15]} \mathrm{Yp}+$ and $\mathrm{Yqh}+$ variants were reported, while reporting polymorphic variants of $\mathrm{Y}$ chromosome. ${ }^{[7,46]}$ Purandare et al. ${ }^{[14]}$ showed that $\operatorname{inv}(\mathrm{Y})$ was related to $\mathrm{BOH}$ leading to first trimester foetal loss in their respective studies. Similarly a highly statistically significant increase in frequency of Yqh+ was observed in men whose wives had BOH. Vaghasia et al. ${ }^{[7]}$ reported inv(Y) and $\mathrm{Yp}+$ were related to infertility. Previous studies have suggested indirect effects such as higher incidence of spontaneous abortions with striking chromosomal variants such as large Y. Though pericentric inversions in $\mathrm{Y}$ are considered to be as normal variant with no possible effect on fertility, ${ }^{[47,48]}$ but a few cases have reported showing infertility. ${ }^{[49-52]}$

$\mathrm{D} / \mathrm{G}$ groups of chromosomes include 13, 14, 15 (D group), 21 and 22 (G group) are the common heteromorphisms showing increased heterochromatin in the chromosome telomere, the short arm and the nuclear organisation region (NOR). Heterochromatin localized in centromere region has an essential role in spindle attachment and chromosome movement, meiotic pairing and sister chromatid cohesion. Chromatin in these regions causes defects in centromere function and kinetochore assembly, abnormal homologous chromosome pairing and impacts on cell division, affecting gamete formation. ${ }^{[2,3,4,53]}$ These groups have higher amounts of heterochromatin in short arms and satellite regions $(15 p s+, 21 p s+, 13 p s k+) .{ }^{[54,55]}$ The stalks contain 18s and 28s rRNA and ribosomal proteins to form nude RNA (NOR). ${ }^{[56]}$ Therefore polymorphism in this region suggests positive association with clinical anomalies as reported by numerous investigators ${ }^{[3,4,7,14,15,35}$ 37,43,57,59] particularly in relation to infertility, BOH and other reproductive anomalies in assisted reproductive results like In-vitro fertilisation (IVF), Pre-implantation genetic diagnosis (PGD), Preimplantation genetic screening (PGS).

Chromosomal analysis has been done in larger groups of infertile patients recently. ${ }^{[2,4,7,14,15,36,60-63]}$ Most of these reports claimed that chromosome polymorphism is higher in infertile and other abnormal cases than in normal population. ${ }^{[2,64]}$ Others had given little or no importance of heteromorphism in reproductive anomalies $^{[46,53]}$ as cited earlier. Comparatively, numerous researchers gave almost importance of it and correlated to loss of reproductive function in both $\operatorname{sexes}^{[7,14,15,32]}$ and these variants are associated with abnormalities of human reproduction. ${ }^{[62,54]}$ The most frequent types of heteromorphism in the infertile group was inv(9) and ' $D$ ' group variants followed by $\mathrm{Yqh}+/ \mathrm{Yqh}$ - and ' $G$ ' group variants. ${ }^{[7,15,32]}$ Their study documented that $\mathrm{D} / \mathrm{G}$ group variants of chromosomes are contributors to infertility in both male and females (Fig.3) as noted by Purandare et al. ${ }^{[7,14]}$ Heterochromatin variations mostly of chromosome 1 and 9 inversions and $\mathrm{qh}+$ are significantly higher in couples with $\mathrm{BOH}$ in their study. Pregnancy losses were also higher in couples with $22 \mathrm{ps}+$ and 15ps+. Thus, the study has called for counseling of couples with $\mathrm{BOH} .^{[14]}$ Hence, the overall prevalence of chromosomal polymorphisms in infertile couples and IVF cases further needs to be confirmed with new investigations and larger study population to delineate the role of harmless chromosomal variants in the etiology of infertility. ${ }^{[34,42,60]}$

Studies carried out by Hong et al. ${ }^{[53]}$ and Dang et al. ${ }^{[46]}$ in their studies from China and North East China claimed that heteromorphism of chromosomes of ' $D$ ' and ' $G$ ' groups including ' $\mathrm{Y}$ ' and their multiples have no much impact on reproductive failure $^{[53]}$ and have no impact on outcome of IVF and also embryo transfer treatment. Therefore more number of samples and better sensitive techniques are needed in this study ${ }^{[46]}$ in relation to infertility. So these heterochromatic regions have importance for clinical disorders like sterility, cancer and developmental problems in the field of clinical genetics in future.

\section{Mechanisms}

Heterochromatic region are considered to be present in 1.9.16, Y, D/G groups of chromosomes in common as identified by GTG banding. It contains junk repeats of DNA. ${ }^{[2]}$ Recently, it also contains genes for regulation of cell function, chromosomal movements and infertility including cancer cited earlier ${ }^{[4,7,17,19,22]}$ with DNA modification and other mechanism. In acrocentric 
chromosomes, nuclear organization region (NOR) contains of rRNA while short arms have heterochromatin. Chromatin modification, including histone core protein changes non coding of small interfering RNA (SiRNA)- related to silencing of gene expression and reverse DNA methylation affect the gene expression which form part of epigenetic alteration (Fig.1).

Certain non acrocentric, heterochromatin regions are related to malignancy/ cancer aneuploidy leading to various types of cancers. The association of constructive heterochromatin and malignancies might reflect on heterochromatin distribution in patients and controls. It also plays a role in chromosomal segregation, pairing and cell division. This has a role in formation of aneuploidies in infertility ${ }^{[17,60,65]}$ and would also be probable cause of cancer types (Fig.1). Certain regions of heterochromatin proteins are also associated with stress stimuli such as heat shock proteins (hsps), which may result in suppression of gene activity/ expression. ${ }^{[66]}$ Pericentric heterochromatin induces silencing effect on euchromatic genes when brought together in a subset of cells in which these genes would otherwise be normally expressed. ${ }^{[2,4,55,67]}$

Further, junk DNA formed by infolding may affect gene coding. This was further referred by Macera et al. ${ }^{[68]}$. The noncoding DNA has a role in the suppression of genes based on biochemical and genetic analysis. It is possible that heterochromatin and euchromatin have inter- convertible nature. Hence, repressed DNA segments of heterochromatin and euchromatin (having expressed/ active segments) are expression of the degree of nuclear differentiation within individually differentiated cells. ${ }^{[69,70]}$ Cellular processes involving depression of previously repressed gene include the activating/ expression of sperm genome in the embryo, viral oncogenesis and alteration of ' $\mathrm{Y}$ ' genes during fetal development. ${ }^{[71]}$ Similarly, $\mathrm{X}$ chromosome inactivation is one of the two XX chromosomes in female animals in response to certain cellular stimuli, which equalizes the expression of $\mathrm{X}$-linked genes in female (XX) and male (XY) embryos. ${ }^{[71]}$ The mechanism for association of chromosomal polymorphic variants with cell functional defects like infertility, malignancy remains to be answered. Data from cytogenetic studies on association of chromosomal variants and clinical conditions like infertility, cancer should not be ignored despite the earlier consensus pointed out that these polymorphic variants are unimportant. $^{[7,72,74]}$

\section{Conclusion}

In conclusion, [Table-1] based on the data available on transcriptional activation of constitutive heterochromatin, the role of heat shock transcription factors nucleolar segregation and capping during transcription inhibition is known. The use of NOR in differentiating malignant and benign tumours and polymorphic chromosome variants and couples with reproductive dysfunction, it would be postulated that NOR and heterochromatin could play a role in certain clinical condition. It is further stressed that chromosome variants should not be ignored by cytogeneticists and clinicians, but should be evaluated for future use as all these variants may not be normal, still infertile couples with variants including aneuploidy and repeated failures may stand better chance with screened gametes. Further development of FISH probes which detect specific variants could enhance the selection of embryos by pre-implantation genetic screening (PGS) and pre implantation genetic diagnosis (PGD) and other clinical conditions in future. For new genetic tests and counseling, more governmental organizations (GO's) and nongovernmental organizations (NGO's) join together to monitor heterochromatic variants in field of assisted reproductive technology (ART) and cancer as well as their role for betterment of the society. $[5,17,30,74,75-80]$

\section{Recommendations}

Chromosomal heteromorphism detection is important in routine karyotypic analysis. Its anomalies cannot be ignored in present molecular technology. Hence, appropriate evaluation of polymorphic variants is necessary using FISH probes to assist the society in future for the affected cases, though few studies indicated ignorance earlier in regard to heterochromatin DNA blocks.

\section{Acknowledgement}

Special thanks are to Dr. K.Mudra, Ms. Krishna Mistry, Ms. Nirzary B, Ms. Samiksha H and authors who helped in preparation of this review in our Neuberg Supratech Laboratories, Ahmedabad, India.

\section{Bibliography}

[1] Mattei MG, Luciani J. Heterochromatin, from chromosome to protein. Atlas of Genetics and Cytogenetics in Oncology and Haematology. Infobiogen, France. 2003.

[2] Madon PF, Athalye AS, Parikh FR. Polymorphic variants on chromosomes probably play a significant role in infertility. Reproductive Biomedicine Online. 2005;11(6):726-732.

[3] Bhasin, MK. Human population genetics: A review. Int J Hum Genet. 2005;83-152.

[4] Minocherhomji S, Athalye AS, Madon PF, Kulkarni D, Uttamchandani SA, Parikh FR. A case-control study identifying chromosomal polymorphic variations as forms of epigenetic alterations associated with the infertility phenotype. Fertility and sterility. 2009;92(1):88-95.

[5] Wyandt HE, Wilson GN, Tonk VS. Human chromosome variation: heteromorphism, polymorphism and pathogenesis. Springer. New York. 2017;PP 37-56.

[6] Liehr T. Cases with heteromorphisms. http://some.tl.com/hms.html (accessed 6/9/2017). 2017.

[7] Vaghasia K, Shah D, Shah S, Bhatt M, Shah C, Rao MV. Karyotypic Analysis of Chromosomal Polymorphism in Relation to Reproductive Failure. International Journal of Pharmacy and Pharmaceutical Sciences. 2017;9(4):140143.

[8] Brothman, A.R., Schneider, N.R., Saikevych, I., Cooley, L.D., Butler, M.G., Patil, S., Mascarello, J.T., Rao, K.W., Dewald, G.W., Park, J.P. and Persons, D.L. Cytogenetic heteromorphisms: survey results and reporting practices of giemsa-band regions that we have pondered for years. Archives of pathology \& laboratory medicine. 2006;130(7): 947-949.

[9] Lundgren R, Berger R, Kristoffersson U. Constitutive heterochromatin $\mathrm{C}$-band polymorphism in prostatic cancer. Cancer genetics and cytogenetics. 1991;51(1):5762.

[10] Caspersson T, Farber S, Foley GE, Kudynowski J, Modest EJ, Simonsson E, Wagh U, Zech L. Chemical differentiation along metaphase chromosomes. Experimental cell research. 1968;49(1):219-222. 
[11] Geraedts JP, Pearson PL. Fluorescent chromosome polymorphisms: frequencies and segregations in a Dutch population. Clinical Genetics. 1974;6(4):247-257.

[12] Lin CC, Gedeon MM, Griffith P, Smink WK, Newton DR, Wilkie L, Sewell LM. Chromosome analysis on 930 consecutive newborn children using quinacrine fluorescent banding technique. Human Genetics. 1976;31(3):315-328.

[13] Lubs HA, Patil SR, Kimberling WJ, Brown J, Cohen M, Gerald P, Hecht F, Myrianthopoulos N, Summit RL. Q and C-banding polymorphisms in 7 and 8 year old children: racial differences and clinical significance. Population Cytogenetic Studies in Humans. Academic Press, New York. 1977;pp133-159.

[14] Purandare H, Fernandes NV, Deshmukh SV, Chavan S. Heterochromatic variations and pregnancy losses in humans. International Journal of Human Genetics. 2011;11(3):167-175.

[15] Pokale YS. Does a Heterochromatic variant affect the Human Reproductive outcome?. Research Journal of Recent Sciences. 2015;2277:2502

[16] Berger R, Bernheim A, Mitelman F, Rydholm A. C-band pattern in lymphocytes of patients with soft tissue sarcomas. Cancer Genetics and Cytogenetics. 1983;9(2):145-150.

[17] Berger R, Bernheim A, Kristoffersson U, Mitelman F, Olsson H. C-band heteromorphism in breast cancer patients. Cancer genetics and cytogenetics. 1985;18(1):37-42.

[18] Babu A, Agarwal AK, Verma RS. A new approach in recognition of heterochromatic regions of human chromosomes by means of restriction endonucleases. American journal of Human Genetics. 1988;42(1):60.

[19] Atkin NB. Chromosome 1 heteromorphism in patients with malignant disease: A constitutional marker for a high-risk group? British medical journal. 1977;1(6057):358.

[20] Atkin NB, Brito-Babapulle V. Heterochromatin polymorphism and human cancer. Cancer Genetics and Cytogenetics. 1981;3(3):262-272.

[21] Atkin NB, Brito-Babapulle V. Chromosome 1 heterochromatin variants and cancer: A reassessment. Cancer Genetics and Cytogenetics. 1985;18(4):325-331.

[22] Kopf I, Islam MQ, Friberg LG, Levan G. Familial occurrence of cancer and heteromorphism of the heterochromatic segment of chromosome 1. Hereditas. 1989;110(1):79-83.

[23] Sumner AT. A simple technique for demonstrating centromeric heterochromatin. Exp. Cell Res. 1972;75:304-306.

[24] Kivi S, Mikelsaar AV. C-band polymorphisms in lymphocytes of patients with ovarian or breast adenocarcinoma. Cancer genetics and cytogenetics. 1987; 28(1):77-85.

[25] Aguilar L, Lisker R, Ruz L, Mutchinick O. Constitutive heterochromatin polymorphisms in patients with malignant diseases. Cancer. 1981;47(10):2437-2439.

[26] Petković I, Nakić M, Čepulić M, Tiefenbach A, Konja J. Variability of chromosomes 1,9 , and 16 in children with malignant diseases. Cancer genetics and cytogenetics. 1985; 16(2):169-173.

[27] Adhvaryu SG, Dave BJ, Trivedi AH, Jani KH, Vyas RC. Heteromorphism of C-band positive chromosomal regions in CML patients. Cancer genetics and cytogenetics. 1987; 27(1):33-38.

[28] Ranni NS, de Vinuesa ML, de Pargament MM, Slavutsky I, Larripa I. Heterochromatic variants and their association with neoplasias: III. Multiple myeloma. Cancer genetics and cytogenetics. 1987; 28(1):101-105.

[29] Suciu S. Constitutive heterochromatin studies in patients with solid tumors. Journal of cancer research and clinical oncology. 1986; 111(3):291-294.

[30] Rao MV, Shah NP, Shah PS, Shah SC, Bhavini SS. Unpublished data.

[31] Potluri VR, Singh IP, Bhasin MK. Human Chromosomal Heteromorphisms in Delhi Newborns. Human heredity. 1985;35(5):333-338.

[32] Saran N, Kumar B, Kumar A. Chromosomal heteromorphisms and karyotype abnormalities in humans. Int J Curr Microbiol Appl Sci. 2017;6(5):29402953.

[33] Kurtovic-Kozaric A, Mehinovic L, Komic H, Kozaric M, Husic-Selimovic A. Human Cytogenetics Case Report Yet Unreported Heteromorphic Variant in Chromosome 17. J Genetics Genomes. 2017;1(101):2.

[34] Mierla DA, Stoian V. Association of pericentric inversion of chromosome 9 and infertility in romanian population. Maedica. 2012a;7(1):25.

[35] Dana M, Stoian V. Association of pericentric inversion of chromosome 9 and infertility in romanian population. Maedica. 2012;7(1):25.

[36] Christofolini DM, Mafra FA, Neto RP, Saab de Almeida Barros RA, Amaro dos Santos A, Peluso C, Gava MM, Milton Ghirelli-Filho M, Bianco B, Barbosa CP. Correlation between chromosomal variants and male infertility in a population of Brazilian infertile men. Reproductive Sys Sexual Disord. 2012;1(1):1-8.

[37] Rao BV, Kerketta L, Korgaonkar S, Ghosh K. Pericentric inversion of chromosome 9 [inv (9)(p12q13)]: Its association with genetic diseases. Indian $\mathrm{J}$ Hum Genet. 2006;12(3):129-132.

[38] Verma RS. A reply: pericentric inversion of chromosome 9qh are" real" but the mechanisms of their origin are highly complex. Human Genetics (Berlin).1999;105:1834.

[39] Nagvenkar P, Desai K, Hinduja I, Zaveri K. Chromosomal studies in infertile men with oligozoospermia \& non-obstructive azoospermia. Indian Journal of Medical Research. 2005;122(1):34.

[40] Dubey S, Chowdhury MR, Prahlad B, Kumar V, Mathur R, Hamilton S, Kabra M, Menon PS, Verma IC. Cytogenetic causes for recurrent spontaneous abortionsan experience of 742 couples (1484 cases). Ind Med Genol. 1(2):94-98.

[41] Mozdarani H, Meybodi AM, Karimi H. Impact of pericentric inversion of Chromosome 9 [inv (9)(p11q12)] on infertility. Indian Journal of Human Genetics. 2007;13(1):26.

[42] Sahin FI, Yilmaz Z, Yuregir OO, Bulakbasi T, Ozer O, Zeyneloglu HB. Chromosome heteromorphisms: an impact on infertility. Journal of assisted reproduction and genetics. 2008; 25(5):191-195.

[43] Jeong SY, Kim BY, Yu JE. De novo pericentric inversion of chromosome 9 in congenital anomaly. Yonsei medical journal. 2010;51(5):775-780. 
[44] Akbas E, Senli H, Hallioglu O, Batmaz S, Erdogan NE. Association of pericentric inversion of chromosome 9 (inv [9][p11q13]) and genetic diseases: case report. Laboratory Medicine. 2010;41(2):96-98.

[45] Kosvakova N, Grigorian A, Liehr T, Manvelyan M, Simonyan I, Mkrtchyan H, Aroutiounian R, Polityko AD, Kulpanovich AI, Egorova T, Jaroshevich E. Heteromorphic variants of chromosome 9. Molecular Cytogenetics. 2013;6(1):14

[46] Dong Y, Jiang YT, Du RC, Zhang HG, Li LL, Liu RZ. Impact of chromosomal heteromorphisms on reproductive failure and analysis of 38 heteromorphic pedigrees in Northeast China. Journal of Assisted Reproduction and Genetics. 2013;30(2):275-281.

[47] Verma RS, Rodriguez J, Dosik H. The quantitative analysis of constitutive heterochromatic regions of human chromosomes 1,9 , and 16 in relation to size and inversion heteromorphisms in East Indians. Experientia. 1982; 38(3):324-326.

[48] Shapiro LR, Pettersen RO, Wilmot PL, Warburton D, Benn PA, Hsu LY. Pericentric inversion of the Y chromosome and prenatal diagnosis. Prenatal diagnosis. 1984; 4(6):463-465.

[49] Ferlin A, Arredi B, Foresta C. Genetic causes of male infertility. Reproductive Toxicology. 2006; 22(2):133141.

[50] Mcelreavey K, Chantot-Bastaraud S, Ravel C, Mandelbaum J, Siffroi JP. Y chromosome and male infertility: what is a normal Y chromosome?. Journal de la Societe de Biologie. 2008; 202(2):135-141.

[51] Ravel C, Chantot-Bastaraud S, El Houate B, Rouba H, Legendre M, Lorenço D, Mandelbaum J, Siffroi JP, McElreavey K. Y-chromosome AZFc structural architecture and relationship to male fertility. Fertility and sterility. 2009; 92(6):1924-1933.

[52] Stouffs K, Vandermaelen D, Tournaye H, Liebaers I, Van AS, Lissens W. Genetics and male infertility. Verhandelingen-Koninklijke Academie voor Geneeskunde van Belgie. 2009; 71(3):115-139.

[53] Hong Y, Zhou YW, Tao J, Wang SX, Zhao XM. Do polymorphic variants of chromosomes affect the outcome of in vitro fertilization and embryo transfer treatment?. Human Reproduction. 2011; 26(4):933-940.

[54] Mitelman F, editor. ISCN 1995: an international system for human cytogenetic nomenclature (1995): recommendations of the International Standing Committee on Human Cytogenetic Nomenclature, Memphis, Tennessee, USA, 1994. Karger Medical and Scientific Publishers; New York.

[55] Borgaonkar DS. Chromosomal variantions in man: A Catalogue of Chromosomal Variants and Anomalies. 8th Ed. New York, Wiley.1997.

[56] Makałowski W. The Human Genome Structure and Organization. Acta Biochim. Pol. 2001; 48:587-598.

[57] Kumar M, Thatai A, Chapadgaonkar SS. Homozygosity and Heterozygosity of the Pericentric Inversion of Chromosome 9 and Its Clinical Impact. Journal of Clinical \& Diagnostic Research. 2012; 6(5).

[58] Sofia CL, Chinnaswami P, Mahalingam K, Chinnaswamy P. Secondary constriction region variations in individuals with reproductive failure. Intl $\mathrm{J}$ Life Sci Res. 2015; 33:40-58.
[59] Etem EÖ, Yüce H, Erol D, Deveci ŞD, Ceylan GG, Elyas H. Original research cytogenetic analysis in infertile males with sperm anomalies. Marmara Medical. 2009; 22(3):217.

[60] Mierla D, Stoian V. Chromosomal polymorphisms involved in reproductive failure in the romanian population. Balkan Journal of Medical Genetics. 2012b; 15(2):23-28.

[61] Cortés-Gutiérrez EI, Cerda-Flores RM, Dávila-Rodríguez MI, Hernández-Herrera R, Vargas-Villarreal J, LealGarza CH. Chromosomal abnormalities and polymorphisms in Mexican infertile men. Archives of Andrology. 2004; 50(4):261-265.

[62] Nakamura Y, Kitamura M, Nishimura K, Koga M, Kondoh N, Takeyama M, Matsumiya K, Okuyama A. Chromosomal variants among 1790 infertile men. International Journal of Urology. 2001; 8(2):49-52.

[63] Lissitsina J, Mikelsaar R, Punab M. Cytogenetic analyses in infertile men. Archives of andrology. 2006; 52(2):9195.

[64] Suganya J, Kujur SB, Selvaraj K, Suruli MS, Haripriya G, Samuel CR. Chromosomal abnormalities in infertile men from southern India. Journal of clinical and diagnostic research: JCDR. 2015; 9(7):GC05.

[65] Patil SR, Lubs HA. Classification of qh regions in human chromosomes 1,9 , and 16 by C-banding. Human genetics. 1977; 38(1):35-3

[66] Rizzi N, Denegri M, Chiodi I, Corioni M, Valgardsdottir R, Cobianchi F, Riva S, Biamonti G. Transcriptional activation of a constitutive heterochromatic domain of the human genome in response to heat shock. Molecular biology of the cell. 2004; 15(2):543-551.

[67] Morimoto RI. Regulation of the heat shock transcriptional response: cross talk between a family of heat shock factors, molecular chaperones, and negative regulators. Genes \& Development. 1998; 12(24):37883796.

[68] Macera MJ, Verma RS, Conte RA, Bialer MG, Klein VR. Mechanisms of the origin of a G-positive band within the secondary constriction region of human chromosome 9. Cytogenetic and Genome Research. 1995; 69(3-4):235-239.

[69] Frenster JH, Herstein PR. Gene de-repression. New England Journal of Medicine. 1973; 288(23):1224-1229.

[70] Nakatsu SL, Masek MA, Landrum S, Frenster JH. Activity of DNA templates during cell division and cell differentiation. Nature. 1974; 248(5446):334.

[71] Sun F, Oliver-Bonet M, Turek PJ, Ko E, Martin RH. Meiotic studies in an azoospermic human translocation (Y; 1) carrier. Molecular human reproduction. 2005; 11(5):361-364.

[72] Chopade S, Chopade DK, Harde H. Impact of chromosomal heteromorphisms on recurrent miscarriages. Human Genet Embryol. 2012; 2(1):101102.

[73] Soudek D, Laraya P. Longer Y chromosome in criminals. Clinical genetics. 1974; 6(3):225-229.

[74] Boronova I, Bernasovska J, Cakanova G, Ferenc P, Petrejcikova E, Szabadosova V. Heterochromatin variants in Slovak women with reproductive failure. International Journal of Human Genetics. 2015;15(1):15. 
[75] Munné S. Preimplantation genetic diagnosis of numerical and structural chromosome abnormalities. Reproductive BioMedicine Online. 2002; 4(2):183-196.

[76] Márquez C, Sandalinas M, Bahçe M, Munné S. Chromosome abnormalities in 1255 cleavage-stage human embryos. Reproductive biomedicine online. 2000; 1(1):17-26.

[77] Fischer J, Colls P, Escudero T, Munné S. PGD improves pregnancy outcome for translocation carriers with a history of recurrent losses. Reproductive BioMedicine Online. 2009; 18:S-12.
[78] Chatziparasidou A, Christoforidis N, Samolada G, Nijs M. Sperm aneuploidy in infertile male patients: a systematic review of the literature. Andrologia. 2015; 47(8):847-60.

[79] Shah NP, Shah PS, Bhatt NH, Vaghasia KV, Shah SP, Rao MV. Aneuploidy analysis of 5740 referral cases. A triemmial report. Int J Hum Genet. In Press. 2019a.

[80] Shah NP, Shah PS, Bhatt NH, Mistry K, Dominic J, Kansara M, Hakim S, Sandip SC, Rao MV. Detection of Sole and Clonal Aneuploidy in Hematologic Malignant Diseases. Biotechnological Research. 2019b; 5(3):16-21. 